\title{
On the Purchasing Power Parity in Turkey: The Role of Structural Changes
}

\author{
Assoc. Prof. Dr. Şaban Nazlığlu (Pamukkale University, Turkey) \\ Ph.D. Candidate Çă̆ın Karul (Pamukkale University, Turkey) \\ Ph.D. Candidate Ahmet Koncak (Abant İzzet Baysal University, Turkey) \\ Assoc. Prof. Dr. İlhan Küçükkaplan (Pamukkale University, Turkey)
}

\begin{abstract}
Turkey as an emerging country and one of the fastest growing economies during the last decade has been implementing the trade-oriented growth model since 1980. The exchange rate policy in that respect is at the center of trade and monetary policies. Given the importance of constructing fundamental equilibrium exchange rates, the long-run PPP hypothesis has been empirically investigated during the last decade. We re-examine the purchasing power parity (PPP) hypothesis for Turkey with her ten major trading partners and find out that when the structural shifts are taken into account, there is a strong evidence in favor of the validity of PPP hypothesis. An interesting finding also is that the PPP hypothesis seems to hold for the European Union countries.
\end{abstract}

\section{Introduction}

Given the importance of determining equilibrium exchange rates, a special attention has been given to testing for the long-run PPP hypothesis during the last decade. The PPP hypothesis implies a stationary real exchange rate series and therefore researchers benefit from the unit root analysis.

Turkey which is an emerging market and a fastly growing economy (during the last decade) has put into effect the trade-oriented growth model in 1980 that leads the exchange rate policy to be at the core of trade and monetary policies. Turkey decided to shift from pegged to flexible exchange rate system because of the 2001 economic crisis and hence the dynamics of Turkish exchange rates play a crucial role for sound monetary policy. The literature on the persistence of shock to Turkish real exchange rates shows that there is no consensus whether the shocks are permanent. The lack of consensus on PPP hypothesis holds for Turkey motivate us to re-examine the PPP hypothesis within the context of new testing procedures.

This study re-analyzes the validity of PPP hypothesis in Turkey by employing a battery of unit root and stationarity tests. This study contributes to the literature by looking at the validity of PPP in Turkey by focusing on modelling the structural changes. Empirical analysis indicates that there is a strong evidence in favor of the validity of PPP hypothesis when the structural shifts are taken into account in testing procedures. It is important to emphasize that even though this finding is not new for international trade literature, it provides a new empirical evidence with respect to the dynamics of exchange rates in Turkey.

\section{Testing Procedures}

\subsection{Unit Root Tests}

To test for unit root of Turkish exchange rates, we first start with the Dickey-Fuller (DF) test developed by Dickey and Fuller (1979) and estimate the no-shift regression model as

$$
\Delta \mathrm{y}_{\mathrm{t}}=\mathrm{Z}_{\mathrm{t}}^{\prime} \delta+\alpha \mathrm{y}_{\mathrm{t}-1}+\varepsilon_{\mathrm{t}}
$$

where $\Delta \mathrm{y}_{\mathrm{t}}$ is the first difference of $y_{t}, \mathrm{Z}_{\mathrm{t}}$ includes the deterministic terms defined by $[1, \mathrm{t}]$, and $\varepsilon_{\mathrm{t}}$ is the error term. The null hypothesis of unit root $\left(\mathrm{H}_{0}: \alpha=0\right)$ is tested against the alternative hypothesis of stationarity $\left(\mathrm{H}_{1}: \alpha<0\right)$. Accordingly, if the null hypothesis is rejected, then an evidence is supported in favor of PPP hypothesis. The test statistic denoted by $\tau$ is defined by the t-ratio of $\alpha$. Under the null hypothesis, the t-ratio corresponds to $y_{t-1}$ does not follow the asymptotic t-distribution and therefore one needs to use the critical values provided by Dickey and Fuller (1979).

In the no-shift model, $\mathrm{Z}_{\mathrm{t}}$ is assumed not to have any structural changes. However, ignoring structural shifts leads to misleading inferences because of incorrectly retaining a false unit root null hypothesis (Perron, 1989). In order to handle this problem, Zivot and Andrews (1992) allow a sudden structural break in the DF test. To formulize the sharp-shift model with one break, $\mathrm{Z}_{\mathrm{t}}$ is described as $\left[1, \mathrm{t}, \mathrm{DU}_{1 \mathrm{t}}, \mathrm{DT}_{1 \mathrm{t}}\right]$ where $\mathrm{DU}_{1 \mathrm{t}}=0$ for $\mathrm{t} \leqslant \mathrm{T}_{\mathrm{B}}$ and 1 otherwise and $\mathrm{DT}_{1 \mathrm{t}}=0$ for $\mathrm{t} \leqslant \mathrm{T}_{\mathrm{B}}$ and $\mathrm{t}-\mathrm{T}_{\mathrm{B}}$ otherwise that $\mathrm{T}_{\mathrm{B}}$ denotes the break date. Narayan and Popp (2010) extend Zivot and Andrews (1992)'s sharp shift model for two sudden breaks that $Z_{t}$ becomes [1, t, $\mathrm{DU}_{1 \mathrm{t}}, \mathrm{DT}_{1 \mathrm{t}}, \mathrm{DU}_{2 \mathrm{t}}, \mathrm{DT}_{2 \mathrm{t}}$ ], where $\mathrm{DU}_{\mathrm{it}}=0$ for $\mathrm{t} \leqslant \mathrm{T}_{\mathrm{Bi}}$ and 1 otherwise and $\mathrm{DT}_{\mathrm{it}}=0$ for $\mathrm{t} \leqslant \mathrm{T}_{\mathrm{Bi}}$ and $\mathrm{t}-\mathrm{T}_{\mathrm{Bi}}$ otherwise and $\mathrm{T}_{\mathrm{Bi}}(\mathrm{i}=1,2)$ shows the break dates. The statistic for testing the null hypothesis of unit root with structural shifts is described as in the DF test. Both Zivot and Adrews (1992) and Narayan and Popp (2010) approaches use the dummy variables to capture sudden structural changes and require estimating the break dates. The location of break $\left(\mathrm{T}_{\mathrm{Bi}}\right)$ is endogenously determined to be where the test statistic is minimized (i.e., the most negative) by a grid search 
procedure by considering all possible break points as $\widehat{\delta}=\inf \tau(\delta)$ where $\delta=\mathrm{T}_{\mathrm{Bi}} / \mathrm{T}$ and $\delta \in[0,1]$. Finally, $\tau$ statistic with structural shifts does not follow the asymptotic t-distribution and hence the simulated critical values are used.

It is worthwhile noting that the sharp-shift models entail knowing a priori the number, dates and form of breaks. In practice, it is however difficult to have such a priori knowledge and moreover economic series may contain multiple smooth breaks at unknown dates. More recently, Enders and Lee (2012) propose the smooth-shift model type of the DF unit root test by using a Fourier approximation for $Z_{t}$ which does not require selecting the dates, number, and form of the breaks. The Fourier expansion for $Z_{t}$ is described as $\left[1, t, \sin \left(\frac{2 \pi k t}{T}\right), \cos \left(\frac{2 \pi k t}{T}\right)\right]$ where $k$ represents an integer frequency. The test statistic is again described as in the DF test, but its distribution now depends on $k$ that requires using the critical values for different values of the Fourier frequency (see, Enders and Lee, 2012). It is finally should be emphasized that the smooth-shift model testing procedure now requires determining the Fourier frequency and the number of lags. Following Enders and Lee (2012), we apply the generalto-specific approach. The maximum number of Fourier frequency is set to 3 and the maximum number of lags is set to 4 . We first determine the optimal lag for each of frequency with the significance of the last lagged term by looking at its t-statistic at the 10 percent level. The optimal number of Fourier frequency component is then selected by the minimization of sum of squared residuals of the regression model.

\subsection{Stationarity Tests}

Testing the null hypothesis of stationarity against the alternative of unit root is one of ongoing research areas in the time series analysis. The stationarity test of Kwiatkowski et al. (1992) (the KPSS test) is widely utilized which is based on the data generating process (DGP)

$$
\begin{aligned}
& y_{t}=\gamma^{\prime} Z_{t}+r_{t}+\varepsilon_{t} \\
& r_{t}=r_{t-1}+u_{t}
\end{aligned}
$$

where $\mathrm{t}=1, \ldots, \mathrm{T}$ time dimension, $r_{t}$ is random walk process with initial values $r_{0}=0$. The null hypothesis of stationarity $H_{0}: \sigma_{u}^{2}=0$ is tested against the alternative hypothesis of unit root. $H_{1}: \sigma_{u}^{2}>0$.

In the conventional KPSS test, $Z_{\mathrm{t}}$ is assumed not to have any structural changes and is defined as $Z_{t}=[1, t]^{\prime}$ for a trend stationary process. Lee et al. (1997) investigates the distribution of the KPSS test under a structural break and find out that the test diverges from the distribution under the null hypothesis when the structural break is ignored. The simulations moreover indicate that the KPSS statistics is over-sized in the case of a structural shift. Kurozumi (2002) allows a break in the KPSS test by defining $Z_{t}$ as $\left[1, t, D_{1 t}, D_{1 t}\right]$ where $D_{1 t}=0$ for $t \leqslant T_{B}$ and 1 otherwise and $\mathrm{DT}_{1 \mathrm{t}}=0$ for $\mathrm{t} \leqslant \mathrm{T}_{\mathrm{B}}$ and $\mathrm{t}-\mathrm{T}_{\mathrm{B}}$ otherwise that $\mathrm{T}_{\mathrm{B}}$ denotes the break date. Carrion-i-Silvestre and Sansó (2007) (hereafter CS) extends the testing framework for two breaks that $Z_{t}$ becomes $\left[1, t, \mathrm{DU}_{1 \mathrm{t}}, \mathrm{DT}_{1 \mathrm{t}}, \mathrm{DU}_{2 \mathrm{t}}, \mathrm{DT}_{2 \mathrm{t}}\right]$, where $\mathrm{DU}_{\mathrm{it}}=0$ for $\mathrm{t} \leqslant \mathrm{T}_{\mathrm{Bi}}$ and 1 otherwise and $\mathrm{DT}_{\text {it }}=0$ for $\mathrm{t} \leqslant \mathrm{T}_{\mathrm{Bi}}$ and $\mathrm{t}-\mathrm{T}_{\mathrm{Bi}}$ otherwise and $\mathrm{T}_{\mathrm{Bi}}(\mathrm{i}=1,2)$ show the break dates. Both Kurozumi and CS approaches use the dummy variables to capture structural shifts and require estimating the location of break $\left(\mathrm{T}_{\mathrm{Bi}}\right)$ which is endogenously determined by minimizing the test statistic by considering all possible breaks points as $\widehat{\delta}=\inf \tau(\delta)$ where $\delta=$ $\mathrm{T}_{\mathrm{Bi}} / \mathrm{T}$ and $\delta \in[0,1]$.

As discussed earlier, the dummy variable approach assumes sharp shifts and also entails to know a priori the number and dates of breaks. In practice, it is difficult to have a such a prior information and moreover economic series may contain an unknown form breaks at unknown dates. Becker et al. (2006) (hereafter BEL) use a Fourier approximation for $Z_{t}$ which does not require selecting the dates, number, and form of the breaks. The Fourier expansion for $Z_{t}$ is described as $\left[1, t, \sin \left(\frac{2 \pi k t}{T}\right), \cos \left(\frac{2 \pi k t}{T}\right)\right]$ where $k$ represents an integer frequency. The testing procedure now requires determining the Fourier frequency. Following Becker et al. (2006), we apply the generalto-specific approach. The maximum number of Fourier frequency is set to 3 and the optimal number of Fourier frequency component is then selected by the minimization of sum of squared residuals of the regression model.

The stationarity statistic is defined as $L M=\frac{\sum_{t=1}^{T} \tilde{S}_{t}^{2}}{\widetilde{\sigma}_{\varepsilon}^{2}}$ where $\tilde{S}_{t}=\sum_{j=1}^{t} \tilde{\varepsilon}_{j}$ is the partial sum process by using the OLS residuals from equation (1) and $\tilde{\sigma}_{\varepsilon}^{2}$ is an estimate of the long-run variance of $\varepsilon_{t}$ that is defined as $\sigma_{\varepsilon}^{2}=$ $\lim _{T \rightarrow \infty} T^{-1} E\left(S_{T}^{2}\right)$ (Note 1). Since LM statistics does not follow the asymptotic t-distribution and hence the simulated critical values are used.

\section{Empirical Findings}

We collect the real exchange rates data between Turkey and Canada, Denmark, Eurozone, Japan, Norway, Saudi Arabia, Sweden, Switzerland, United Kingdom, and USA for the period January 2002-December 2016 (Note 2). The period is started from January 2002 because the euro banknotes and coins were put into circulation from that time. We describe the real exchange rate by $y_{i t}=e_{i t}+p_{i t}^{*}-p_{t}$ where $\mathrm{e}$ is the natural logarithm of nominal 
exchange rates, $p^{*}$ is the natural logarithm of foreign CPI and $\mathrm{p}$ is the natural logarithm of domestic CPI which are based the indexes $(2010=100)$. The data is retrieved from the International Financial Statistics (IFS).

Table 1 reports the results from the unit root and stationarity tests. The Panel A is for the results from the unit root tests. The no-shift model indicates that the PPP hypothesis seems to be valid only for Norway. When we account for the one-sharp structural change, the PPP is supported in six trading partners (Denmark, Japan, Norway, Sweden, Switzerland, and UK). Moreover, if the number of structural changes raises to two-sharp shifts, the PPP appears to be valid for all countries. If the structural changes are modelled as a gradual/smooth process, the PPP is supported for six countries (Denmark, Eurozone, Norway, Sweden, Switzerland, and UK) which are all the European Union countries during the sample period.

Testing null hypothesis of stationarity is useful to confirm results those from the tests with the null hypothesis of unit root. The conventional KPSS test shows that the null hypothesis of stationarity cannot be rejected in for countries (Canada, Denmark, Eurozone, and Norway), implying that the PPP holds. If we account for sharp structural change, while the PPP is supported in nine countries partners (except UK) for the one-shift model, it is supported in all the countries for the two-shift model. If the structural changes are modelled as a gradual/smooth process, the PPP is rejected only for two countries (Japan and Sweden). The model with sharp shifts assume that the trend is not strictly linear and hence is composed to a pre-specified number of discrete linear segments. Moreover, there may be a discontinuity at the breakpoint because the end and start of linear segments do not need to be concur. Last but not least, the sharp shift assumption requires an immediate transition from one segment to another. An arguably more realistic approach is to accommodate structural changes as a gradual process (King and Dobson, 2014). From this point of view, the results taken together from both the unit root and stationarity tests based on the smooth-shift model provide an interesting finding is that the PPP hypothesis seems to hold for Denmark, Eurozone, Norway, Switzerland, and UK which are the European Union countries and is not valid for Canada, Japan, Saudi Arabia, Sweden, and USA.

\begin{tabular}{|c|c|c|c|c|c|c|c|c|}
\hline \multirow[b]{2}{*}{ Panel A: Unit root tests } & \multirow{2}{*}{$\frac{\text { No-shift }}{\text { Stat. }}$} & \multicolumn{5}{|c|}{ Sharp-shift } & \multicolumn{2}{|c|}{ Smooth-shift } \\
\hline & & Stat. & Break & Stat. & First Break & Second Break & Stat. & $\mathrm{k}$ \\
\hline Canada & -1.803 & -4.509 & $2005 \mathrm{M} 03$ & -5.185 & 2006M01 & $2011 \mathrm{M} 11$ & -3.043 & 1 \\
\hline Denmark & -2.938 & -5.413 & $2005 \mathrm{M} 04$ & -7.110 & 2008M10 & 2011M04 & -4.321 & 1 \\
\hline Eurozone & -3.016 & -4.568 & 2007M07 & -6.632 & 2008M10 & 2011M04 & -4.468 & 1 \\
\hline Japan & -2.563 & -5.953 & 2008M07 & -7.357 & 2008M07 & $2012 \mathrm{M} 10$ & -3.510 & 2 \\
\hline Norway & -3.445 & -5.354 & 2004M03 & -7.386 & 2004M03 & 2010M10 & -4.672 & 1 \\
\hline Saudi Arabia & -2.404 & -3.634 & $2007 \mathrm{M} 02$ & -5.900 & 2008M07 & 2013M08 & -3.080 & 1 \\
\hline Sweden & -2.653 & -5.487 & 2010M10 & -7.180 & $2006 \mathrm{M} 03$ & 2010M10 & -4.296 & 1 \\
\hline Switzerland & -2.533 & -5.953 & 2008M07 & -6.462 & 2008M07 & $2010 \mathrm{M} 10$ & -4.107 & 1 \\
\hline UK & -2.337 & -5.169 & 2009M10 & -6.886 & 2006M03 & 2009M10 & -4.926 & 1 \\
\hline USA & -1.955 & -3.569 & $2007 \mathrm{M} 07$ & -5.319 & $2007 \mathrm{M} 07$ & 2012M08 & -3.635 & 1 \\
\hline \multicolumn{9}{|l|}{ Panel B: Stationarity tests } \\
\hline Canada & 0.097 & $\mathbf{0 . 0 3 0}$ & 2010M12 & 0.030 & $2007 \mathrm{M} 11$ & 2011M01 & 0.044 & 1 \\
\hline Denmark & 0.117 & 0.025 & 2007M05 & 0.019 & 2002M05 & 2008M02 & 0.023 & 1 \\
\hline Eurozone & 0.118 & 0.024 & 2011M01 & 0.021 & 2002M05 & 2008M02 & 0.020 & 1 \\
\hline Japan & 0.189 & 0.024 & 2008M09 & 0.024 & 2008M09 & 2012M12 & 0.169 & 2 \\
\hline Norway & 0.117 & 0.019 & $2010 \mathrm{M} 12$ & 0.038 & $2003 \mathrm{M} 03$ & $2011 \mathrm{M} 01$ & 0.024 & 1 \\
\hline Saudi Arabia & 0.750 & 0.045 & 2008M09 & 0.033 & 2008M09 & 2012M12 & 0.027 & 1 \\
\hline Sweden & 0.149 & 0.024 & 2010M12 & 0.023 & 2002M05 & 2010M12 & 0.050 & 1 \\
\hline Switzerland & 0.229 & 0.031 & 2008M09 & 0.016 & 2002M05 & 2008M02 & 0.034 & 1 \\
\hline UK & 0.364 & 0.070 & 2010M12 & 0.039 & 2010M12 & 2015M05 & 0.026 & 1 \\
\hline USA & 0.581 & 0.032 & 2007M09 & 0.027 & 2008M09 & 2012M11 & 0.028 & 1 \\
\hline
\end{tabular}

Bold numbers denote that PPP hypothesis is valid at least at $10 \%$ level of significance.

Table 1: Empirical Results

\section{Conclusion}

We examine the PPP hypothesis in Turkey based on the unit root framework and benefits from the recent developments in time series testing procedures by paying attention to controlling for structural shifts. We first estimate the no-shift model and then employ its extensions to which accounting for structural breaks, namely the sharp-shift model and the smooth-shift model. The results from the point of modelling strategy imply that controlling for structural shifts plays an important role in order to determine the behavior of Turkish exchange rates.

The different testing strategies result in the different inferences and policy implications. The conventional noshift model unit root and stationarity models imply the PPP is valid only for Norway. In contrast to the no-break test, the sharp shift tests based two-break model description show the strong evidence on the PPP. Finally, the testing procedure -based on the assumption that any structural shifts are gradual in nature- supports that the PPP hypothesis seems to hold for Denmark, Eurozone, Norway, Switzerland, and UK which are the European Union countries and is not valid for Canada, Japan, Saudi Arabia, Sweden, and USA. 


\section{Acknowledgements}

Saban Nazlioglu gratefully acknowledges that this study is carried out under the Outstanding Young Scientists Award Program-2015 of the Turkish Academy of Sciences (TÜBA-GEBIP 2015).

\section{References}

- Adiguzel, U., Sahbaz, A., Ozcan, C.C., Nazlioglu, S. (2014). The Behavior of Turkish Exchange Rates: A Panel Data Perspective. Economic Modelling, 42, 117-185.

- Becker, R., Enders, W., Lee, J. (2006). A Stationarity Test in the Presence of an Unknown Number of Smooth Breaks. Journal of Time Series Analysis 27, 381-409.

- Carrion-i-Silvestre, J.L., Del Barrio-Castro, T., Lopez-Bazo, E., (2005). Breaking the panels: An application to GDP per capita, Econometrics Journal, 8, 159-175.

- Carrion-i-Silvestre, J. Ll., Sansó, A., (2006). A guide to the computation of stationarity tests. Empirical Economics, 31, 433-448.

- Carrion-i-Silvestre, J.L., Sansó-i-Rosselló, A.S. (2007). The KPSS Test with Two Structural Breaks. Spanish Economic Review, 9(2), 105-127.

- Dickey, D.A. and Fuller, W.A., (1979). Distribution of the Estimators for Autoregressive Time Series with a Unit Root. Journal of the American Statistical Association, 74(366), 427-431.

- Enders, W. and Lee, J. (2012). The flexible Fourier form and Dickey-Fuller type unit root tests. Economics Letters, 117, 196-199.

- King, A. and Dobson, R.C. (2014). Are income differences within the OECD diminishing? Evidence from fourier unit root tests. Studies in nonlinear dynamics and econometrics, 18, 185-199.

- Koedijk, K.G., Tims, B., Dijk, M.A. (2004). Purchasing Power Parity and the Euro Area, Journal of International Money and Finance. 23, 1081-1107.

- Kurozumi, E. (2002). Testing for Stationarity with a Break. Journal of Econometrics. 108(1), 63-99.

- Kwiatkowski, D., Phillips, P.C.B., Schmidt, P., Shin, Y. (1992). Testing the Null Hypothesis of Stationary against the Alternative of a Unit Root. Journal of Econometrics 54,159-178.

- Lee, J., Huang, C.J., Shin, Y. (1997). On Stationary Tests in the Presence of Structural Breaks. Economics Letters, 55, 165-172.

- Narayan, P.K. and Popp, S. (2010). A new unit root test with two structural breaks in level and slope at unknown time. Journal of Applied Statistics, 37, 1425-1438.

- Perron, P. (1989). The Great Crash, the Oil Price Shock and the Unit Root Hypothesis, Econometrica, 57, 1361-1401.

- Zivot, E., and Andrews, D.W.K. (1992). Further evidence of the great crash, the oil-price shock, and the unit root hypothesis. Journal of Business \& Economic Statistics, 10, 251-270.

\section{Footnotes:}

(Note 1) See Carrion-i-Silvestre and Sansó (2006) for the methods on estimating the consistent long-run variance and their small sample comparisons.

(Note 2) The selected trading partners account for about $97 \%$ and $96 \%$ of Turkish total exports and imports which is generally quoted by euro and US dollar. Following Koedijk et al. (2004), we treat the Eurozone countries as a single currency. The euro explains about 48 percent of Turkey's exports and 30 percent of Turkish imports (see, Adiguzel et al., 2014). 